\title{
Correction to: Description of a new species of seed-gall nematode, Anguina obesa n. sp. (Nematoda: Anguinidae) from northern Iran, and its phylogenetic relations with other species and genera
}

\author{
Mahyar Mobasseri • Majid Pedram • \\ Ebrahim Pourjam • Terry Bertozzi \\ Published online: 9 March 2018 \\ (C) Koninklijke Nederlandse Planteziektenkundige Vereniging 2018 \\ Correction to: Eur J Plant Pathol \\ https://doi.org/10.1007/s10658-016- \\ 1101-9
}

In the original version of this article, the name of host plant Alopecurus myosuroides was incorrectly written as Alopecurus mysuroides.

The online version of the original article can be found at https://doi.org/10.1007/s10658-016-1101-9

M. Mobasseri $\cdot$ M. Pedram $(\bowtie) \cdot$ E. Pourjam

Department of Plant Pathology, Faculty of Agriculture, Tarbiat,

Modares University, Tehran, Iran

e-mail: majid.pedram@modares.ac.ir

e-mail: mj_pedram@yahoo.com

T. Bertozzi

Evolutionary Biology Unit, South Australian Museum, Adelaide,

SA 5000, Australia

T. Bertozzi

School of Biological Sciences, University of Adelaide, North

Terrace, Adelaide, SA 5005, Australia 